\title{
Simulation of Power Generation from Vibration of Railway Track
}

\author{
Fiona Mercy Akello, 2, *, Lucky Ugochukwu Adoh ${ }^{1,3}$ \\ ${ }^{1}$ African Railway Center of Excellence, Addis Ababa Institute of Technology, Addis Ababa University, Addis Ababa, Ethiopia \\ ${ }^{2}$ Mechanical Engineering Department, Kyambogo University, Kampala, Uganda \\ ${ }^{3}$ Department of Mechanical Engineering, Federal University of Technology, Akure, Ondo State, Nigeria
}

Email address:

akello.fiona@aait.edu.et (F. M. Akello)

${ }^{*}$ Corresponding author

To cite this article:

Fiona Mercy Akello, Lucky Ugochukwu Adoh. Simulation of Power Generation from Vibration of Railway Track. International Journal of Sustainable and Green Energy. Vol. 9, No. 1, 2020, pp. 16-22. doi: 10.11648/j.ijrse.20200901.12

Received: March 15, 2020; Accepted: March 30, 2020; Published: April 13, 2020

\begin{abstract}
Ethiopia has a small percentage of its population accessing electricity with some power utilized by its transportation sector; there are frequent power outages that slow down economic activities such as trade and railway transportation. From this previous statement, it is clear that the demand for energy is significantly increasing and there is too much dependability on the current energy source. With the development of sustainable energy technology in the world today, this problem can be alleviated, while utilizing component vibration in railway infrastructure. The aim of this study was to estimate energy generation potential from the vibration of a railway track induced by a passing train using a two degree of freedom oscillator. Data was collected; energy harvesting system was modeled and simulated. Based on the result, the system produces enough energy to power communication and signaling equipment on the track. The optimum parameters: mass of $1 \mathrm{~kg}$, a spring stiffness of $6 \mathrm{~N} / \mathrm{m}$ and a damping coefficient of $4 \mathrm{Ns} / \mathrm{m}$ of the energy harvester were determined using sensitivity analysis. The cumulative mechanical power harvested by the inter-city-125 train at a speed of $195 \mathrm{~km} / \mathrm{h}$ was calculated to be $224.56 \mathrm{~W}$. Therefore, the energy demand of the communication and signaling equipment of the train track can be achieved using vibration energy harvesting system by installing the number that meets the demand.
\end{abstract}

Keywords: Electricity, Energy Harvested, Mechanical Energy, Two Degree of Freedom Oscillator, Vibration

\section{Introduction}

Energy is the main driver of the economy of one country and living without access to energy is very challenging. Ethiopia is a country with approximately 110 Million population and Electricity is available for $41 \%$ of the population, but only $17 \%$ of households are connected to the central grid, all in major towns and cities [1]. Even though, Ethiopia is endowed with vast energy resources, only $5 \%$ of Hydropower, less than $1 \%$ of Solar energy, about $3.24 \%$ of Wind Energy potential and about $50 \%$ of Biomass potential has been exploited [2, 3]. Based on the 2016 Energy Statistics yearbook data published by united nation, the net installed capacity of electricity in Ethiopia is $4.238 \mathrm{GW}$ out of which $99 \mathrm{MW}$ is generated from combustible fuel, 3.808
GW from hydropower, $324 \mathrm{MW}$ from Wind and $7 \mathrm{MW}$ from other sources [4].

In September 2015, Ethiopian introduced the first light rail transits system at Addis Ababa city (ALART). The tram currently consists of two lines (one north-south and one east west direction) covering 34 kilometers and serving 39 stations [5]. Besides, the light rail transit system, the 750 kilometers Ethio-Djibouti standard gauge Railway, which was built jointly by Ethiopia and Djibouti started operation on January 1, 2018 and is accelerating its impact on economy [5]. The light rail transit system in Addis Ababa and the Ethio-Djibouti railway lines consumes huge amount of energy of the installed $4.238 \mathrm{GW}$ of net installed capacity of electricity.

Several researches have been done to harvest energy from a moving train over the past decades. Most of the existing 
railway energy harvesting technologies focus on low power applications and uses two ways to harvest energy from railway track vibration, i.e., Piezoelectric and Electromagnetic harvesters [6]. These low power applications include; Simulation of a program to detect obstacles on the right of way of trains, flood on the railway track and smoke in the train [7], could also be used for safety demonstration and risk management at rail-road level crossing [8]. An energy harvesting pad composed of piezoelectric stacks developed by Israeli company Innowattech Ltd was installed under the rail fastener and it can harvest large energy from the track vibration [9]. Even though this technology is effective in harvesting vibration energy, it needs to drill on the sleeper and the size of piezoelectric generator is limited $[6,9]$. Tawaris et al (2013) highlighted that piezoelectric material is advantageous in harvesting vibration energy due to their large power densities and ease of applications [10]. When vibration input is applied; due to the piezoelectric effect, the piezoelectric generator generates electricity using piezoelectric material. Platt et al. (2005) mentioned that piezoelectric stack of thickness vibration is an effective method of energy harvesting large mechanical vibration [11]. However, Zhao Hongduo's research revealed that power generation capacity of piezoelectric stack is not high because of its high stiffness [9, 12].

Feng et al. (2018) highlighted that in order to realize larger force and power outputs with a small input, hundreds of thin piezoelectric films can be mechanically layered together in series and electronically connected in parallel so as to compromise a multilayer piezoelectric stack. In doing so the efficiency and power output is increased significantly. Xie et al (2017) concluded that in comparison with various well studied piezoelectric beam harvesters, the modeling and analysis of piezoelectric stack transducers are still underdeveloped [13]. Besides, knowing the electromechanical coupling behavior of the piezoelectric stack under various excitations is very critical and predicting accurately the electrical responses including voltage, current and power outputs of the piezoelectric stack transducer is important aspect for the success piezoelectric stack transducer $[13,14]$.

Investigation of energy harvesting from train vibrations for low power wireless sensors was done by the French national railway system [15]. Piezoelectric transducers are devices able to generate a voltage, between 3 to $10 \mathrm{~V}$ [16], without requiring a pre-charge to work [17]. Piezoelectric materials are, however, very sensitive to temperature, and therefore need to be applied in environment with limited temperature variability [18]. If piezoelectric materials are subject to high temperatures, they can become de-polarized and inoperative. Generally piezoelectric converters produce a current that is not compatible in microelectronics, but have a high voltage generated compared to electromagnetic converters [19].

There is a possibility of generating power by tapping vibration energy using a mass spring damper system (oscillator). A comprehensive investigation on this topic was recently presented by the authors in [20], where energy was harvested from the track-side vibration, induced by the passage of a train, as a specific practical application of time limited excitation, where there is only significant vibration input for the duration of the train passage. A single degree of freedom oscillator was investigated by Gatti et al [20] to find the maximum available energy that could be potentially harvested from a passing train. Using an acceleration time history of vertical vibration measured on a sleeper during the passage of an Inter-city 125 train in the United Kingdom, passing at a speed of about $195 \mathrm{~km} / \mathrm{h}$, the optimum mechanical parameters of a linear energy harvesting device are determined. A numerical and analytical study was done; it was found that the maximum energy that could be harvested per unit mass of the oscillator is about $0.25 \mathrm{~J} / \mathrm{kg}$ at a frequency of about $17 \mathrm{~Hz}$.

Jang et al., et al. (2009) showed that the single degree of freedom vibration-based Energy harvesting device generates the maximum power when its natural frequency matches the ambient frequency. However, this condition is difficult to guarantee when the excitation is not controllable or intrinsically frequency variant over a broad bandwidth [21]. Renno et al. (2009) highlighted that the bandwidth of the energy harvesting device also can be enhanced by sophisticated electronics [22].

Energy harvesting has been done before by various authors who used different harvesting mechanisms like piezoelectric materials, electromagnetic mechanism and many others. However, these technologies' output power is low, mechanical friction is a challenge, air drag is increased by wind turbines and limited researches has been done to harvest energy from a moving train using a two degree of freedom oscillator.

The aim of this study was to simulate energy harvested from vibration of a passing train using two degrees of freedom oscillator. Data collection of the vibration profile, modeling of the system using a damped mass spring two degree of freedom and simulation has been done to know the energy harvesting potential of the Addis Ababa Light Rail Transit Railway. Considering the electricity power problem of Addis Ababa city, generating additional source of electricity helps the country at large. This harvested energy can be used to power communication and signaling equipment.

\section{Methodology}

\subsection{Vibration Data}

Vibrations occurs due to the wheel/rail interaction and they can be subdivided as trainload excitation (quasi-static excitation), roughness excitation, flat wheel and others, known as dynamic excitation [23]. Thompson [24] compared the quasi-static and dynamic excitation, and showed that the quasi-static is dominant at low frequencies (between 25 to $50 \mathrm{~Hz}$, depending on the train speed) and generates high levels of vibration on the 
sleepers. Dynamic excitations are dominant at higher frequencies (higher than 25 to $50 \mathrm{~Hz}$ depending on the train speed) due to the roughness between the wheel/rail interactions. Secondary data of the Inter- city 125 train at a speed of $195 \mathrm{~km} / \mathrm{h}$ was collected. The vibrational characteristics of the Inter- city -125 train were obtained and depicted as shown in Figure 1 as Acceleration vs time and Amplitude vs frequency curve.

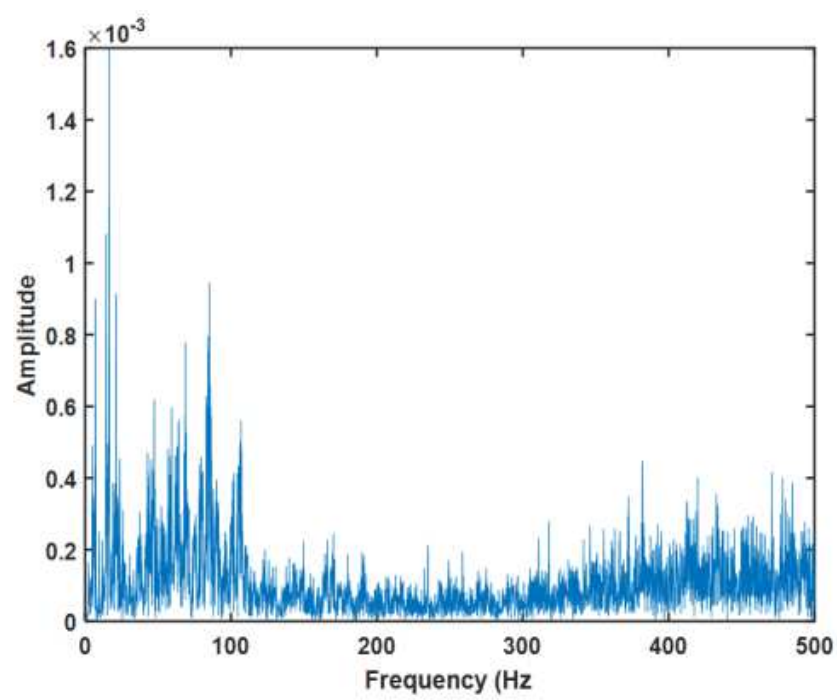

(a)

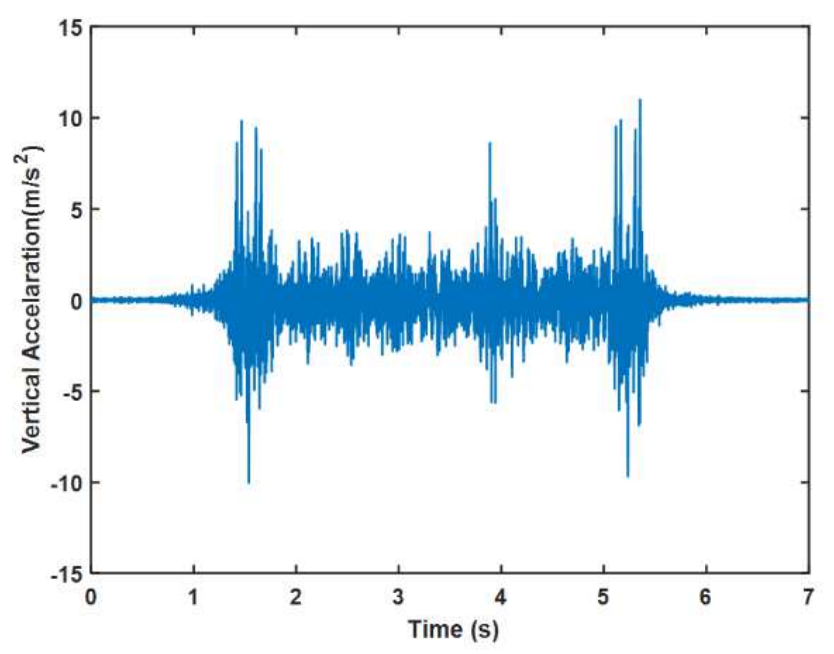

(b)

Figure 1. Measured vertical acceleration of a sleeper as an Inter-city 125 train passes: (a) time history and (b) Amplitude spectrum of the sleeper acceleration

Figure 1a shows that the train induces vibration on the track for about 4 seconds. From figure $1 \mathrm{~b}$ the amplitude spectrum of the sleeper acceleration shows the dominant frequencies. The dominant frequencies, corresponding to the highest peaks are at about $7.14 \mathrm{~Hz}, 14.29 \mathrm{~Hz}, 16.57 \mathrm{~Hz}$, and $21.29 \mathrm{~Hz}$.

\subsection{Modeling the Energy Harvester as a Damped Two}

\section{Degree of Freedom Oscillator}

The energy harvester is a two degree of freedom massspring-damper oscillator enclosed in a rigid housing. This Oscillator is placed under the sleeper from which the vibrating base transmits vertical vibration to the seismic mass through the spring and damper. The schematic representation of the Energy Harvester is shown in figure 2. The following points have been assumed for the modeling.

1. The vibration of the energy harvesting device does not affect the vibration of the sleeper.

2. The energy harvested is the same as the energy dissipated by the damper, therefore identifying the ideal upper limit case where no mechanical loss is considered.

3. Electrical energy harvested is equal to the mechanical energy dissipated

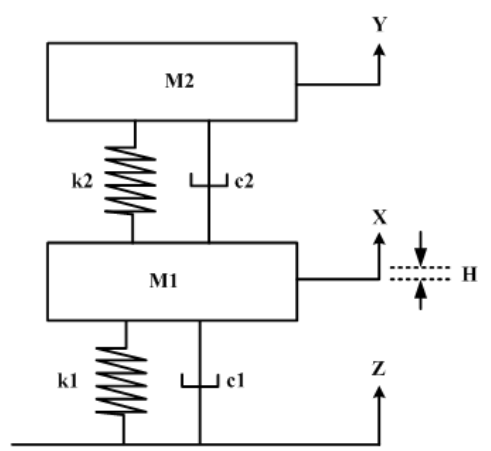

Figure 2. Model of a two degree of freedom, damped spring- mass system.

where;

$\mathrm{M}_{1}$ and $\mathrm{M}_{2}$ are masses, $\mathrm{k}_{1}$ and $\mathrm{k}_{2}$ are the spring stiffness, $\mathrm{c}_{1}$ and $\mathrm{c}_{2}$ are the damping coefficient, $\mathrm{X}, \mathrm{Y}, \mathrm{Z}$ are the displacements of mass 1 , mass 2 and the casing respectively and $\mathrm{H}$ is the relative displacement of the energy harvester

Assume a linear spring and damper system with $\mathrm{x}=0, \mathrm{y}=$ 0 , when the system is in static equilibrium (allows gravity to be neglected as the sum of all force acting on a body need to be equal to the time rate of change of momentum).

$$
\sum F=m a
$$

Mass 1

$$
\begin{gathered}
F k_{1}+F c_{1}-F k_{2}-F c_{2}=M_{1} \ddot{x} \\
F k_{1}=k_{1}(x-z) \\
F c_{1}=c_{1}(\dot{x}-\dot{z}) \\
F k_{2}=k_{2}(y-x) \\
F c_{2}=c_{2}(\dot{y}-\dot{x})
\end{gathered}
$$

Mass 2

$$
-F k_{2}-F c_{2}=M_{2} \ddot{y}
$$

\subsection{Equation of Motion of the Harvesting System}

The derivation of the equations is based upon a Newtonian approach, as the Newton's Second Law is applied to a free 
body diagram. The equation of motion is shown in equation (8 and 9) from newton's second law of motion. This equation is solved using state space equation in Matlab to get the maximum relative displacement of the two degree of freedom oscillator with an input of vibration force. The velocity of the signal is found using cumulative trapezoidal integration of the input acceleration signal in figure 1 (a). Likewise, the displacement of the input signal is found using cumulative trapezoidal integration of the input velocity signal. The input vibration force is put into the state space equation. The relative mass displacement of the two degree of freedom oscillator is obtained from the state space equations. After substituting equations $3,4,5$ and 6 in to 2 and 7 , the equations of motion of the energy harvester can be written as:

$$
\begin{gathered}
\mathrm{m}_{1} \ddot{\mathrm{x}}+\left(\mathrm{c}_{1}+\mathrm{c}_{2}\right) \dot{\mathrm{x}}+\left(\mathrm{k}_{1}+\mathrm{k}_{2}\right) \mathrm{x}-\mathrm{k}_{2} \mathrm{y}-\mathrm{c}_{2} \dot{\mathrm{y}}=\mathrm{k}_{1} \mathrm{z}+\mathrm{c}_{1} \dot{\mathrm{z}} \\
\mathrm{m}_{1} \ddot{\mathrm{y}}+\mathrm{k}_{2} \mathrm{y}+\mathrm{c}_{1} \dot{\mathrm{y}}-\mathrm{c}_{1} \dot{\mathrm{x}}-\mathrm{k}_{2} \mathrm{x}=0
\end{gathered}
$$

Using State space;

$$
\begin{aligned}
& \dot{x}_{2}=\frac{-\left(k_{1}+k_{2}\right)}{m_{1}} x_{1}(t)-\frac{\left(c_{1}+c_{2}\right)}{m_{1}} x_{2}(t)+\frac{k_{2}}{m_{1}} x_{3}(t)+\frac{c_{2}}{m_{1}} x_{4}(t)+\frac{F}{m_{1}} \\
& y=x_{3} \\
& \mathrm{~F}=\mathrm{k}_{1} \mathrm{z}+\mathrm{c}_{1} \dot{\mathrm{z}} \\
& \dot{x}_{4}=\frac{k_{2}}{m_{2}} x_{1}(t)+\frac{c_{2}}{m_{2}} x_{2}(t)-\frac{k_{2}}{m_{2}} x_{3}(t)-\frac{c_{2}}{m_{2}} x_{4}(t) \\
& \left\{\begin{array}{l}
\dot{x}_{1} \\
\dot{x}_{2} \\
\dot{x}_{3} \\
\dot{x}_{4}
\end{array}\right\}=\left[\begin{array}{cccc}
0 & 1 & 0 & 0 \\
\frac{-\left(k_{1}+k_{2}\right)}{m_{1}} & \frac{-\left(c_{1}+c_{2}\right)}{m_{1}} & \frac{k_{2}}{m_{1}} & \frac{c_{1}}{m_{1}} \\
0 & 0 & 0 & 1 \\
\frac{k_{2}}{m_{2}} & \frac{c_{2}}{m_{2}} & -\frac{k_{2}}{m_{2}} & -\frac{c_{2}}{m_{2}}
\end{array}\right]\left[\begin{array}{l}
x_{1} \\
x_{2} \\
x_{3} \\
x_{4}
\end{array}\right]+\left[\begin{array}{c}
0 \\
\frac{1}{m_{1}} \\
0 \\
0
\end{array}\right] F(t)
\end{aligned}
$$

where;

$\mathrm{k}_{1}$ and $\mathrm{k}_{2}$ is the spring stiffness

$\mathrm{c}_{1}$ and $\mathrm{c}_{2}$ are the damping coefficients

$m_{1}$ and $m_{2}$ are the masses of the energy harvester

$\ddot{\mathrm{x}}, \dot{\mathrm{x}}$ and $\mathrm{x}$ are mass $\mathrm{m}_{1}$ acceleration, velocity and displacement respectively. $\ddot{y}, \dot{y}$ and $y$ are mass $m_{2}$ acceleration, velocity and displacement respectively. $\mathrm{F}$ is the input force from the sleeper vibration ( $\mathrm{z}$ being the displacement due to vibration and $\dot{z}$ being the velocity of the vibration). The above state space equation is solved in Matlab to find the relative displacement of the mass system.

\subsection{Simulation of the Energy Harvested from Two DOF Oscillator}

The energy simulated is mechanical energy from which electrical energy can be converted and used to supply axle counters. The energy harvested is calculated based using equation 13 [20];

$$
E(t e)=\int_{0}^{t e} c \dot{z}^{2} d t
$$

where;

$\mathrm{c}$ is the damping coefficient of $\mathrm{c} 1$ and $\mathrm{z}$ is the input signal

A, B, C, D are the respective matrices of the mechanical system defined as follows;

$$
\begin{gathered}
A=\left[\begin{array}{cccc}
0 & 1 & 0 & 0 \\
\frac{-\left(k_{1}+k_{2}\right)}{m_{1}} & \frac{-\left(c_{1}+c_{2}\right)}{m_{1}} & \frac{k_{2}}{m_{1}} & \frac{c_{1}}{m_{1}} \\
0 & 0 & 0 & 1 \\
\frac{k_{2}}{m_{2}} & \frac{c_{2}}{m_{2}} & -\frac{k_{2}}{m_{2}} & -\frac{c_{2}}{m_{2}}
\end{array}\right] \\
B=\left[\begin{array}{c}
0 \\
\frac{1}{m_{1}} \\
0 \\
0
\end{array}\right]
\end{gathered}
$$

\section{Results and Discussion}

\subsection{Model of the Two-degree-of-freedom oscillator (Energy Harvester)}

According to the schematic representation of a $2 \mathrm{DOF}$ oscillator, the model has two masses each of displacement $\mathrm{x}$ and $y$ respectively, supported by springs and damping elements represented by standard symbols whose properties are represented by $\mathrm{k}$ and $\mathrm{c}$ in the case of suspension stiffness and damping respectively. After the base input vibration is input into $2 \mathrm{DOF}$ Oscillator, the maximum relative 
displacement of the mass is limited to $\mathrm{H}$, which is the relative displacement between the mass 1 and the casing. The optimum mass relative displacement shown in figure 3 starts increasing gradually from $5 \mathrm{~Hz}$ to $19.5 \mathrm{~Hz}$ frequency and there after destabilizes. The optimum mass relative displacement whose magnitude is $150 \mathrm{~mm}$ happens at 19.14 $\mathrm{Hz}$ frequency as shown in Figure 3.

\subsection{Sensitivity Analysis}

The effect of damping coefficient, mass and spring stiffness was checked. According to figure 4, it was found that the most effective damping coefficient resulting in the highest energy harvested is $5.5 \mathrm{Ns} / \mathrm{m}$. It can also be observed the highest energy harvested takes place at the $19.14 \mathrm{~Hz}$ natural frequency. During the calculation of the optimum energy harvested, 5.5 damping coefficient shall be used. In addition, energy is harvested at a reasonable amount from 10 $\mathrm{Hz}$ to $19.27 \mathrm{~Hz}$ at intervals, with $1.61 \mathrm{~Hz}$ being the largest interval before the energy diminishes to zero; it remains at zero for $0.63 \mathrm{~Hz}$ after every interval. According to figure 5, the higher the spring stiffness, the higher the energy harvested, in this case, $10 \mathrm{~N} / \mathrm{m}$ being the highest spring stiffness. It is observed that there is no energy harvested from $0 \mathrm{~Hz}$ to $10 \mathrm{~Hz}$. Also, a significant amount of energy is harvested from $11.67 \mathrm{~Hz}$ to $19.27 \mathrm{~Hz}$, there after diminishing to zero, where it stays constant at zero. The natural frequency at which energy harvested is highest is $19.14 \mathrm{~Hz}$ and the lowest natural frequency is $7.643 \mathrm{~Hz}$. After the sensitivity analysis is done, optimum parameters such as mass of $1 \mathrm{~kg}$, spring constant of $6 \mathrm{~N} / \mathrm{m}$ and damping coefficient of $4 \mathrm{Ns} / \mathrm{m}$ is used as the system has the maximum relative displacement and the highest energy harvested as shown in figures 3 and 7 respectively.

The effect of damping coefficient, spring stiffness, and mass on energy harvested was formulated in Matlab from equation (24) of energy harvested. The energy harvested is found for the respective damping coefficient range $(3 \mathrm{Ns} / \mathrm{m}$ to $4.5 \mathrm{Ns} / \mathrm{m}$ ) and the result is in line with literature data [20]. A graph of energy harvested against natural frequency is plotted to see the effect of damping coefficient on energy harvested. The whole procedure of finding energy harvested is repeated with a spring stiffness range of $4.5 \mathrm{~N} / \mathrm{m}, 5 \mathrm{~N} / \mathrm{m}$, $5.5 \mathrm{~N} / \mathrm{m}$, and $6 \mathrm{~N} / \mathrm{m}$. A graph of energy harvested against natural frequency is plotted to see the effect of spring stiffness on energy harvested. The whole procedure of finding energy harvested is repeated with a mass range of 1 $\mathrm{kg}, 1.5 \mathrm{~kg}$ and $2 \mathrm{~kg}$. A graph of energy harvested against natural frequency is plotted to see the effect of mass on energy harvested. Sensitivity analysis has been done by varying the damping coefficient from 3 to $4.5 \mathrm{Ns} / \mathrm{m}$. Where $\mathrm{c}_{11}, \mathrm{c}_{12}, \mathrm{c}_{13}$ and $\mathrm{c}_{14}$ are the damping coefficient used for the sensitivity analysis.

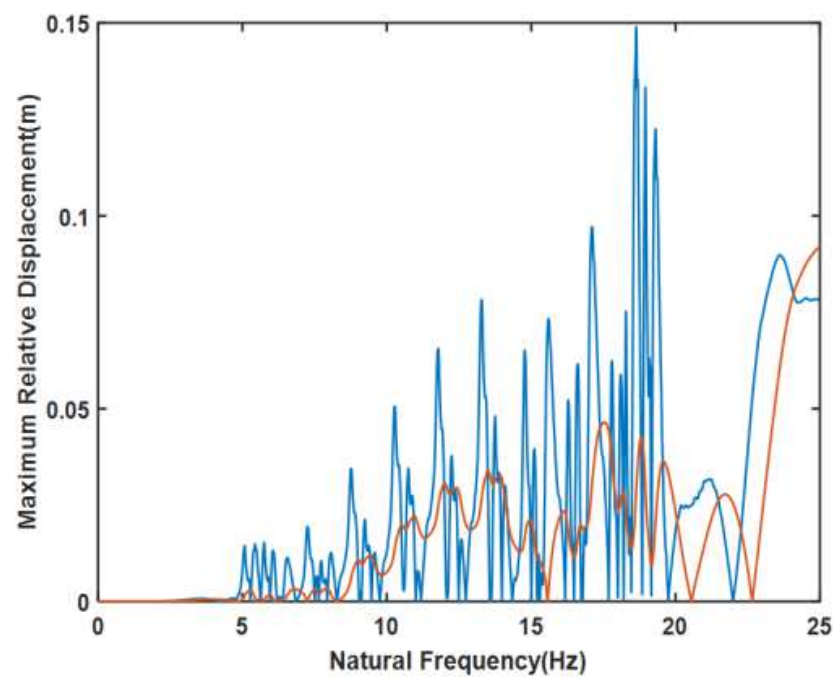

Figure 3. Optimum mass relative displacement.

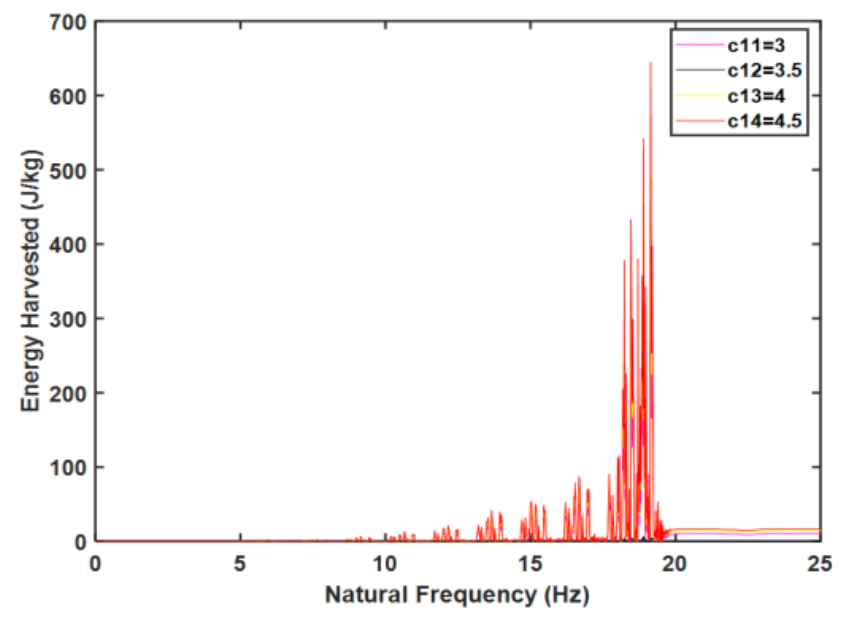

Figure 4. Sensitivity analysis of energy harvested with respect to different damping coefficients.

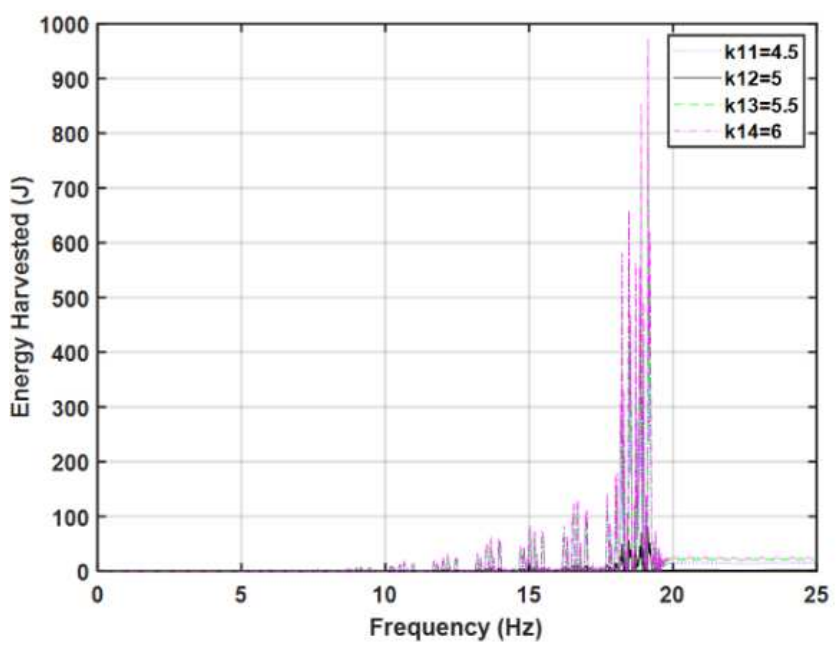

Figure 5. Sensitivity analysis of energy harvested with respect to effect of spring stiffness on Energy harvested. 


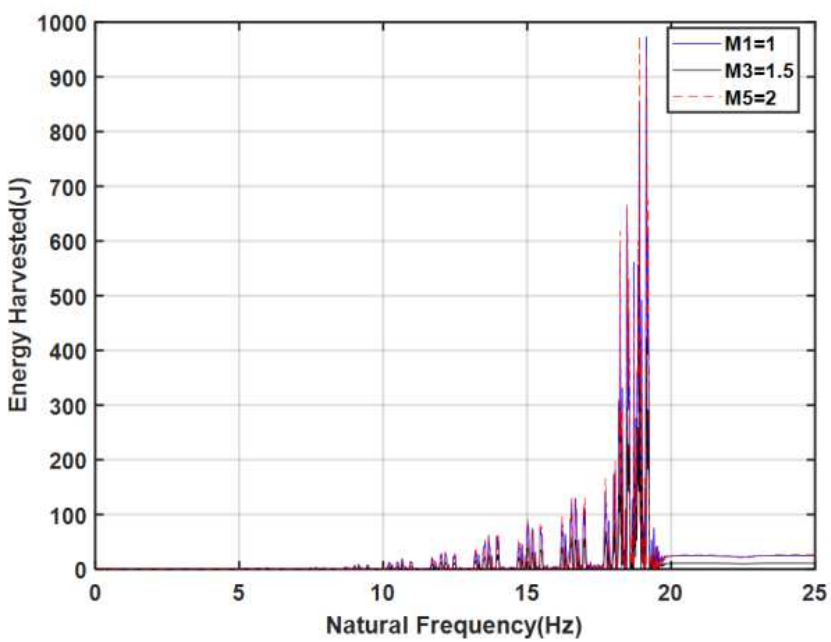

Figure 6. Effect of Mass on Energy harvested.

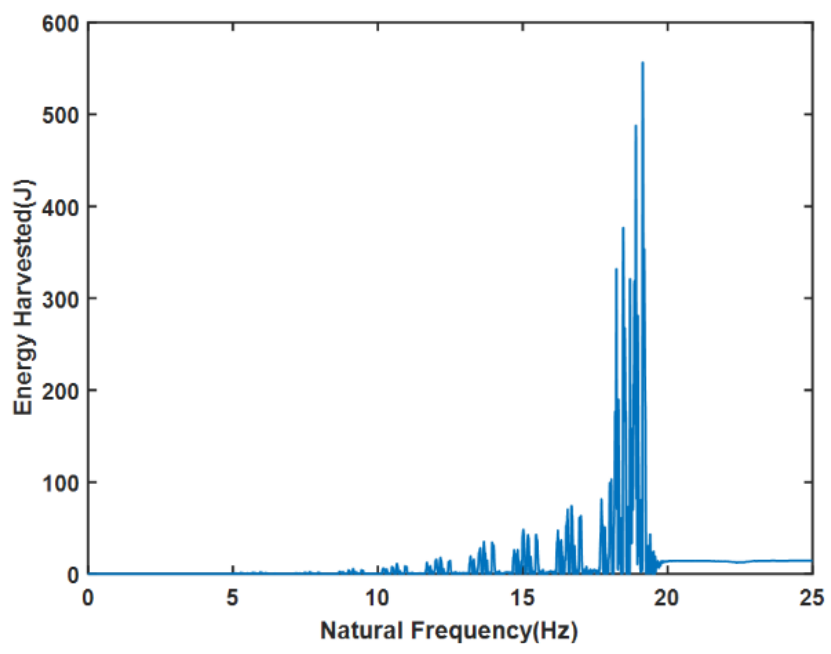

Figure 7. Optimum energy harvested.

\subsection{Cumulative Energy Harvested}

According to figure 7, the lowest natural frequency which marks the beginning of energy harvested is $7.643 \mathrm{~Hz}$. A Matlab code was used to calculate the cumulative energy harvested for the inter-city 125 train. Based on the result, $224.56 \mathrm{~W}$ can be harvested.

\subsection{Power Consumption of Communication and Signaling Equipment}

The power requirements of some track side equipment at Addis Ababa Light Rail Train include; $20 \mathrm{~W}$ for an axle counter, $110 \mathrm{~W}$ for a level crossing, $380-400 \mathrm{~V}$ for a point machine and $220 \mathrm{~V}$ for signal lights. Data was collected from the Kality Depot and power substation so as to calculate the power consumption of the communication and signaling equipment at the Kality depot and main line. Main line data was collected for one substation, so finding the power consumption of communication and signaling equipment of the 20 substations, the power consumption of the Kality substation is multiplied by 20 . The Power consumption of communication and signaling equipment at Depot and main line are $13.752 \mathrm{~kW}$ and $86.896 \mathrm{~kW}$ respectively. It gives a total power consumption of the communication and signaling equipment of Addis Ababa Light Rail Train as $100.65 \mathrm{~kW}$. This energy requirement can be obtained by using 448 oscillators.

\section{Conclusions}

In conclusion, a 2DOF energy oscillator was modeled from the vibration of a passing train to power communication and signaling equipment on the track. The effect of damping coefficient, spring stiffness and mass of the oscillator was investigated. It is observed that as the spring stiffness increases, the rate at which energy is harvested also increases; this can be attributed to the two DOF being employed in the study. Any mass from $1 \mathrm{~kg}$ and above has the same energy harvested, while any mass below gives a higher energy harvested. The relative displacement was found to be $150 \mathrm{~mm}$. The natural frequency at which energy harvested is highest is $19.14 \mathrm{~Hz}$ and the lowest natural frequency is $7.643 \mathrm{~Hz}$. The cumulative mechanical power harvested by the inter-city 125 train at a speed of 195 $\mathrm{km} / \mathrm{h}$ was calculated to be $9,487.75 \mathrm{~W}$ which meets the total power consumption of the communication and signaling equipment of AALRT main line and Kality depot. This 2DOF oscillator meets the energy demand of some way side equipment i.e. the communication and signaling equipment. Future work should be done to investigate the performance of an energy harvester using a nonlinear two degree of freedom mass spring-damper system. Formulate an algorithm of calculating the energy harvested using a multidegree of freedom oscillator. Finally, investigation of how much electrical energy can be harvested and stored from the 2DOF oscillator.

\section{Conflict of Interest Statement}

The authors declare that they have no competing interests.

\section{Acknowledgements}

Authors acknowledge the financial support of the Vice President for Research and Technology Transfer Office of Addis Ababa University.

\section{References}

[1] FDRE, "Federal Democratic Republic of Ethiopia Ministry of Water and Energy Scaling-Up Renewable Energy Program Ethiopia Investment Plan (Draft Final)," no. January, 2012.

[2] K. Gebrehiwot, M. A. H. Mondal, C. Ringler, and A. G. Gebremeskel, "Optimization and cost-benefit assessment of hybrid power systems for off-grid rural electrification in Ethiopia," Energy, vol. 177, pp. 234-246, 2019. 
[3] Hydrochina Corporation, "Master Plan Report of Wind and Solar Energy in the Federal Democratic Republic of Ethiopia," HydroChina Corp., no. July, p. 236, 2012.

[4] 2016 Energy Statistics Yearbook, “02i.pdf." UN, 2019, Newyork, USA, p. 542, 2016.

[5] C. Nallet, The Challenge of Urban Mobility A Case Study of Addis Ababa Light Rail, Ethiopia, no. February. 2018.

[6] J. J. Wang, G. P. Penamalli, and L. Zuo, "Electromagnetic energy harvesting from train induced railway track vibrations," Proc. 2012 8th IEEE/ASME Int. Conf. Mechatron. Embed. Syst. Appl. MESA 2012, vol. 11787, pp. 29-34, 2012.

[7] L. U. Adoh, F. M. Akello, F. Nyangassa, and P. Ishimwe, "Prevention of Railway Accident using Arduino Based Safety System: A case Study of Addis Ababa Light Rail Transit," Int. J. Eng. Res. Technol., vol. 8, no. 09, 2019.

[8] L. U. Adoh, L. Mutswatiwa, and F. M. Akello, "Safety Demonstration and Risk Management at Rail-Road Level Crossing at Addis Ababa Light Rail Transit Network," IJSRSET, vol. 6, no. 5, 2019.

[9] Y. Tianchen, Y. Jian, S. Ruigang, and L. Xiaowei, "Vibration energy harvesting system for railroad safety based on running vehicles," Smart Mater. Struct., vol. 23, no. 12, 2014.

[10] S. M. Taware and S. P. Deshmukh, "A Review of Energy Harvesting From Piezoelectric Materials," J. Mech. Civ. Eng., vol. 4, pp. 43-50, 2013.

[11] S. R. Platt, S. Farritor, and H. Haider, "On Low-frequency electric power generation with PZT ceramics," IEEE/ASME Trans. Mechatronics, vol. 10, no. 2, pp. 240-252, 2005.

[12] H. Zhao, Y. Tao, Y. Niu, and J. Ling, "Harvesting energy from asphalt pavement by piezoelectric generator," J. Wuhan Univ. Technol. Mater. Sci. Ed., vol. 29, no. 5, pp. 933-937, 2014.

[13] X. D. Xie, A. Carpinteri, and Q. Wang, "A theoretical model for a piezoelectric energy harvester with a tapered shape," Eng. Struct., vol. 144, pp. 19-25, 2017.
[14] C. Lee et al., "Theoretical comparison of the energy harvesting capability among various electrostatic mechanisms from structure aspect," Sensors Actuators, A Phys., 2009.

[15] O. Gatin and B. Lhenoret, "Energy Harvesting for Railway Applications, Presentation at Energy Harvesting \& Storage USA 2009," in Presentation at Energy Harvesting \& Storage USA 2009, Denver, CO., 2009.

[16] H. A. Sodano, D. J. Inman, and G. Park, "Comparison of piezoelectric energy harvesting devices for recharging batteries," J. Intell. Mater. Syst. Struct., 2005.

[17] Y. C. Shu and I. C. Lien, "Efficiency of energy conversion for a piezoelectric power harvesting system," J. Micromechanics Microengineering, 2006.

[18] H. A. Sodano, J. Granstrom, J. Feenstra, and K. Farinholt, "Harvesting of electrical energy from a backpack using piezoelectric shoulder straps," in Active and Passive Smart Structures and Integrated Systems 2007, 2007.

[19] R. Gherca and R. Olaru, "Harvesting Vibration Energy by Electromagnetic Induction," Ann. Univ. Craiova, Electr. Eng. Ser., 2011.

[20] G. Gatti, M. J. Brennan, M. G. Tehrani, and D. J. Thompson, "Harvesting energy from the vibration of a passing train using a single-degree-of-freedom oscillator," Mech. Syst. Signal Process., 2016.

[21] S. J. Jang, H. J. Jung, M. J. Brennan, and E. Rustighi, "Design of 2DOF energy harvesting device," no. 8242, pp. 850-859, 2009.

[22] J. M. Renno, M. F. Daqaq, and D. J. Inman, "On the optimal energy harvesting from a vibration source," J. Sound Vib., vol. 320, no. 1-2, pp. 386-405, 2009.

[23] I. Solteira, "Effects of Railway Track Vibration Induced by Passing Trains on an Energy Harvesting Device," 2015.

[24] D. J. Thompson, "Railway Noise and Vibration, Mechanics, Modelling and Means of Control," New YorkElsevier, p. 536, 2009. 